\title{
KECAKAPAN SISWA BERMATEMATIKA MELALUI PENGUATAN PENDIDIKAN KARAKTER ABAD 21
}

\author{
Hartadi Gatot \\ SMP Negeri 1 Palu \\ hartadigatot2@gmail.com
}

\begin{abstract}
ABSTRAK
Matematika merupakan salah satu mata pelajaran yang mempunyai keunikan dari segi pemecahan masalah. Hal ini didasari atas penyelesaian soal yang berkaitan dengan matematika bisa dilalui dengan berbagai macam cara. Hal ini membutuhkan semangat kreativitas sehingga dapat membangun diri peserta didik menjadi insan yang kreatif dan inovatif dalam menyelesaikan suatu masalah. Dalam proses pembelajaran, guru dapat menggunakan pendekatan, strategi, model, atau metode pembelajaran inovatif berupa pembelajaran berbasis masalah (Problem-based learning), salah satu pembelajaran yang mencerminkan pembelajaran abad 21 adalah PBL4C, merupakan salah satu model pembelajaran inovatif yang dapat memberikan kondisi belajar aktif secara mandiri kepada siswa dengan mengarahkan siswa untuk bersamasama (gotong royong) memecahkan suatu masalah dan tentunya hasil akhir dari pembelajaran ini siswa mampu merepresentasikan suatu karya yang terkait dengan berbagai persoalan dalam Matematika. Penerapan kegiatan instruksional PBL4C didasarkan pada strategi pembelajaran yang melibatkan penalaran semantik, penalaran berbasis kasus, penalaran analogis, penalaran kausal, dan penalaran penyelidikan. Terdapat lima fase tahap pelaksanaan pembelajaran berbasis masalah yaitu (1) mengorientasikan siswa pada masalah,(2) mengorganisasi siswa untuk belajar, (3) membimbing penyelidikan individu maupun kelompok, (4) mengembangkan dan menyajikan hasil karya dan (5) menganalisis dan mengevaluasi proses pemecahan masalah.
\end{abstract}

Kata Kunci: $P P K, P B L A C$

\begin{abstract}
Mathematics is one of the subjects that is unique in terms of problem solving. This is based on solving problems related to mathematics can be passed in various ways. This requires a spirit of creativity so that students can develop themselves into creative and innovative people in solving problems. In the learning process, teachers can use innovative learning approaches, strategies, models, or methods in the form of problem-based learning, one of the learning that reflects 21st century learning is PBLAC, is one of the innovative learning models that can provide learning conditions independently to students by directing students to work together (mutual cooperation) to solve a problem and of course the end result of this learning students are able to represent a work related to various problems in Mathematics. The application of PBLAC instructional activities is based on learning strategies involving semantic reasoning, case-based reasoning, analogical reasoning, causal reasoning, and inquiry reasoning. There are five phases of the implementation of problem-based learning, namely (1) orienting students to problems, (2) organizing students to learn, (3) guiding individual or group investigations, (4) developing and presenting work and (5) analyzing and evaluating processes solution the problem.
\end{abstract}

Keywords : PPK, PBLAC 


\section{PENDAHULUAN}

Seiring dengan perkembangan zaman, pendidikan juga mengalami perubahan pesat. Hal ini karena adanya tuntutan zaman terhadap dunia pendidikan, maka dilakukan reformasi mulai dalam sistem pendidikan hingga ke proses pembelajarannya, misalnya perubahan pada kurikulum, penciptaan dan pemanfaatan berbagai media pembelajaran, dan perubahan paradigma pendidikan dari yang teacher centre ke student centre dan perubahan-perubahan lainnya. Sebelum perubahan paradigma pembelajaran yang berpusat pada guru, siswa hanya dijadikan objek pembelajaran, dan guru merupakan subjek pembelajaran, guru merupakan satusatunya sumber belajar, sehingga siswa sangat tergantung pada sosok guru. Untuk meningkatkan kualitas proses dan hasil belajar, para ahli pembelajaran telah menyarankan penggunaan paradigma pembelajaran konstruktivistik untuk kegiatan belajar-mengajar di kelas, hal ini di tunjukkan dengan adanya perubahan kurikulum KTSP menjadi kurikulum 2013 yang terfokus pada kecakapan siswa dalam bermatematika yang terintegrasikan dalam pendekatan scientific. Dengan paradigma ini, pembelajaran selalu diprioritaskan pada siswa. Kegiatan pembelajaran didesain sedemikian rupa agar lebih banyak melibatkan siswa, mendorong siswa untuk lebih kreatif dan belajar mandiri. Dalam proses pembelajaran, guru dapat menggunakan pendekatan, strategi, model, atau metode pembelajaran inovatif berupa pembelajaran berbasis masalah (Problembased learning 4 core areas), selanjutnya disingkat PBL4C, merupakan salah satu model pembelajaran inovatif yang dapat memberikan kondisi belajar aktif kepada siswa dengan mengarahkan siswa untuk bersama-sama memecahkan suatu masalah. Berikut akan dibahas lebih rinci tentang pembelajaran berbasis masalah tersebut.

\section{PEMBAHASAN}

\section{A. Defenisi PPK dan Problem Based Learning 4 core Areas (PBL4C) \\ Suyanto (2009) mendefinisikan} karakter sebagai cara berpikir dan berperilaku yang menjadi ciri khas tiap individu untuk hidup dan bekerja sama, baik dalam lingkup keluarga, masyarakat, bangsa, maupun negara. Menurut kamus psikologi, karakter adalah kepribadian ditinjau dari titik tolak etis atau moral, misalnya kejujuran seseorang, dan biasanya berkaitan dengan sifat-sifat yang relatif tetap (Dali Gulo, 1982). Nilai-nilai dalam pendidikan karakter Ada 18 butir nilai-nilai pendidikan karakter yaitu , Religius, Jujur, Toleransi, Disiplin, Kerja Keras, Kreatif, Mandiri, Demokratis, Rasa Ingin Tahu, Semangat Kebangsaan, Cinta tanah air, Menghargai prestasi, Bersahabat/komunikatif, Cinta Damai, Gemar membaca, Peduli lingkungan, Peduli sosial, Tanggung jawab. Butir-butir nilainilai pendidikan karakter itu di rumuskan menjadi lima nilai karakter utama yang bersumber dari pancasila yang menjadi prioritas pengembangan gerakan PPK yaitu religious, nasionalisme, interitas, kemandirian dan gotong royong.

Apa dampak pendidikan karakter terhadap keberhasilan akademik? Beberapa penelitian bermunculan untuk menjawab pertanyaan ini. Ringkasan dari beberapa penemuan penting mengenai hal ini diterbitkan oleh sebuah buletin, Character Educator, yang diterbitkan oleh Character Education Partnership.

Dalam buletin tersebut diuraikan bahwa hasil studi Dr. Marvin Berkowitz dari University of Missouri- St. Louis, menunjukan peningkatan motivasi siswa sekolah dalam meraih prestasi akademik pada sekolah-sekolah yang menerapkan pendidikan karakter. Kelas-kelas yang secara komprehensif terlibat dalam pendidikan karakter menunjukkan adanya penurunan drastis pada perilaku negatif siswa yang dapat menghambat keberhasilan akademik.

Sebuah buku yang berjudul Emotional Intelligence and School Success (Joseph Zins, et.al, 2001) mengkompilasikan berbagai hasil penelitian tentang pengaruh positif kecerdasan emosi anak terhadap keberhasilan di sekolah. Dikatakan bahwa ada sederet faktor-faktor resiko penyebab kegagalan anak di sekolah. Faktor-faktor resiko yang disebutkan ternyata bukan terletak pada kecerdasan otak, tetapi pada karakter, yaitu rasa percaya diri, kemampuan bekerja sama, kemampuan bergaul, kemampuan berkonsentrasi, rasa empati, dan kemampuan berkomunikasi. 
Hal itu sesuai dengan pendapat Daniel Goleman tentang keberhasilan seseorang di masyarakat, ternyata 80 persen dipengaruhi oleh kecerdasan emosi, dan hanya 20 persen ditentukan oleh kecerdasan otak (IQ). Anakanak yang mempunyai masalah dalam kecerdasan emosinya, akan mengalami kesulitan belajar, bergaul dan tidak dapat mengontrol emosinya.

Anak-anak yang bermasalah ini sudah dapat dilihat sejak usia pra-sekolah, dan kalau tidak ditangani akan terbawa sampai usia dewasa. Sebaliknya para remaja yang berkarakter akan terhindar dari masalahmasalah umum yang dihadapi oleh remaja seperti kenakalan, tawuran, narkoba, miras, perilaku seks bebas, dan sebagainya.

Beberapa negara yang telah menerapkan pendidikan karakter sejak pendidikan dasar di antaranya adalah; Amerika Serikat, Jepang, Cina, dan Korea. Hasil penelitian di negara-negara ini menyatakan bahwa implementasi pendidikan karakter yang tersusun secara sistematis berdampak positif pada pencapaian akademis.

Seiring sosialisasi tentang relevansi pendidikan karakter ini, semoga dalam waktu dekat tiap sekolah bisa segera menerapkannya, agar nantinya lahir generasi bangsa yang selain cerdas juga berkarakter sesuai nilai-nilai luhur bangsa dan agama.

Problem Based Learning 4 core areas (selanjutnya baca PBL4C) merupakan salah satu inovasi pendidikan. Berdasarkan defenisi dari Wikipedia problem based learning is a student-centered instructional strategy in which students collaboratively solve problems and reflect on their experiences.

Dari pengertian di atas dijelaskan bahwa PBL4C adalah suatu strategi pembelajaran yang berpusat pada siswa, starategi ini mengkolaborasikan antara pemecahan masalah dan refleksi terhadap suatu pengalaman. Penerapan kegiatan instruksional PBL4C didasarkan pada strategi pembelajaran yang melibatkan penalaran semantik, penalaran berbasis kasus, penalaran analogis, penalaran kausal, dan penalaran penyelidikan, Selain itu, menurut Fogarty (1997) PBL4C memiliki karakteristik-karakteristik sebagai berikut: (1) belajar dimulai dengan suatu masalah, (2) memastikan bahwa masalah yang diberikan berhubungan dengan dunia nyata siswa/siswa, (3) mengorganisasikan pelajaran diseputar masalah, bukan diseputar disiplin ilmu, (4) memberikan tanggung jawab yang besar kepada pebelajar dalam membentuk dan menjalankan secara langsung proses belajar mereka sendiri, (5) menggunakan kelompok kecil, dan (6) menuntut pebelajar untuk mendemontrasikan apa yang telah mereka pelajari dalam bentuk suatu produk atau kinerja. Pada hakekatnya karakteristik PBL4C ini menciptakan pembelajaran yang menantang siswa untuk memecahkan berbagai masalah yang dihadapi dengan menjalin kerjasama dengan siswa lain, dan guru hanya berperan sebagai fasilitator. Jadi pembelajaran berpusat pada siswa.

\section{B. Kelebihan Problem Based Learning 4 Core Areas}

Pemanfaatan PBL4C (Problem based learning the four core areas) dalam pembelajaran bisa dipandang cocok dengan Kurikulum 2013. Hal ini disebabkan PBL4C merupakan salah satu pengembangan model pembelajaran berbasis masalah yang memiliki beberapa ciri yaitu pembelajaran diawali dengan pemberian masalah kontekstual terhadap siswa, siswa bekerja secara kelompok, siswa belajar memecahkan permasalahan dengan cara diskusi, masalah yang diberikan tidak terbatas hanya pada 1 disiplin ilmu, permasalahan lebih bersifat open-ended, dan siswa harus aktif. Jadi, dalam PBL4C siswa juga dituntut untuk mengamati permasalahan, saling bertanya jawab dan mengumpulkan informasi untuk kemudian menalar guna menemukan solusi yang tepat serta mengkomunikasikan dengan orang lain melalui presentasi kerja kelompok. Setiap kelompok dimungkinkan memiliki penyelesaian yang berbeda dengan kelompok lain. Selama diskusi kelompok siswa juga berlatih untuk belajar saling menghargai, saling menerima, saling membantu dan lainlain. Jadi, pemanfaatan PBL4C dalam pembelajaran ini dapat digunakan untuk meningkatkan karakter siswa sehingga siswa memiliki pengetahuan dan keterampilan yang 
tinggi serta memiliki sikap yang baik. Hal ini selaras dengan Kurikulum 2013 bahwa dalam setiap pembelajaran siswa dituntut untuk dapat meningkatkan beberapa kompetensi diantaranya yaitu peningkatan sikap spiritual, sikap sosial, pengetahuan maupun keterampilan.

Menurut Marmon \& Warabhorn (2013) bahwa : PBLAC is a hybrid model integrating the 4 core areas of learning : 1) Multi-disciplinary content knowledge, 2) Multi-dimensional skills, 3) Appropriate thought dan 4) Universal harmonious values.

C. Teknik Penerapan Problem Based Learning 4 core Areas dalam Pembelajaran dengan 5 nilai-nilai karakter

Penerapan PBL4C dalam proses pembelajaran memerlukan persiapanpersiapan. Salah satunya yaitu menetapkan permasalahan atau tugas (triggering problem/question), dengan syarat; 1) masalah tidak mempunyai struktur yang jelas sehingga siswa/siswa terdorong untuk membuat sejumlah hipotesis dan mengkaji berbagai kemungkinan penyelesaian masalah (praduga ini menguatkan prinsip religius bahwa dperlukan hipotesis untuk menjawab suatu permasalahan); 2) masalah cukup kompleks dan ambigu, sehingga siswa/mahasiwa terdorong untuk menggunakan strategi-strategi penyelesaian masalah dan keterampilan berpikir yang tinggi, seperti melakukan analsis dan sintesis, evaluasi, dan pembentukan pengetahuan dan pengalaman baru (sikap mandiri atau sekaligus bisa bersama-sama menyelesaikan masalah); 3) Bermakna dan ada hubungannya dengan kehidupan nyata siswa/siswa, sehingga mereka termotivasi untuk mengarahkan dirinya sendiri dan menguji pengetahuan/pemahaman lama mereka dalam menyelesaikan tugas tersebut (diperlukan sikap integritas dan nasionalisme untuk bisa mencapai kebermaknaan). Arends (2004) juga merinci langkah-langkah pelaksanaan PBL dalam pengajaran, ada 5 fase (tahap) yang perlu dilakukan untuk mengimplementasikan PBL. Fase-fase tersebut merujuk pada tahap-tahapan praktis yang dilakukan dalam kegiatan pembelajaran. Fase tersebut, dapat diuraikan sebagai berikut:
Fase Aktivitas guru

Fase 1:

Mengorientasikan siswa pada masalah. Guru/dosen menjelaskan tujuan pembelajaran, logistik yang diperlukan, memotivasi siswa terlibat aktif pada aktivitas pemecahan masalah yang dipilih.

\section{Fase 2:}

Mengorganisasi siswa untuk belajar. Guru/dosen membantu siswa membatasi dan mengorganisasi tugas belajar yang berhubungan dengan masalah yang dihadapi. guru/dosen dapat memulai kegiatan pembelajaran dengan membentuk kelompokkelompok siswa dimana masing-masing kelompok akan memilih dan memecahkan masalah yang berbeda. Prinsip-prinsip pengelompokan siswa dalam pembelajaran kooperatif dapat digunakan dalam konteks ini seperti: kelompok harus heterogen, pentingnya interaksi antar anggota, komunikasi yang efektif, adanya tutor sebaya, dan sebagainya.

\section{Fase 3:}

Membimbing penyelidikan individu maupun kelompok. Pada tahap ini, guru/dosen harus mendorong siswa untuk mengumpulkan data dan melaksanakan eksperimen (mental maupun aktual) sampai mereka betul-betul memahami dimensi situasi permasalahan. Tujuannya adalah agar siswa mengumpulkan cukup informasi untuk menciptakan dan membangun ide mereka sendiri.

\section{Fase 4:}

Mengembangkan dan menyajikan hasil karya. Guru/dosen membantu siswa merencanakan dan menyiapkan karya yang sesuai seperti laporan, video, dan model, dan membantu mereka untuk berbagi tugas dengan temannya. Langkah selanjutnya adalah mempamerkan hasil karyanya dan guru berperan sebagai organisator pameran. Akan lebih baik jika dalam pemeran ini melibatkan siswa-siswa lainnya, guru-guru, orangtua, dan lainnya yang dapat menjadi "penilai" atau memberikan umpan balik.

\section{Fase 5:}

Menganalisis dan mengevaluasi proses pemecahan masalah. Selama fase ini guru meminta siswa untuk merekonstruksi pemikiran dan aktivitas yang telah dilakukan selama proses kegiatan belajarnya. Kapan mereka pertama kali memperoleh 
pemahaman yang jelas tentang situasi masalah? Kapan mereka yakin dalam pemecahan tertentu? Mengapa mereka dapat menerima penjelasan lebih siap dibanding yang lain? Mengapa mereka menolak beberapa penjelasan? Mengapa mereka mengadopsi pemecahan akhir dari mereka? Apakah mereka berubah pikiran tentang situasi masalah ketika penyelidikan berlangsung? Apa penyebab perubahan itu? Apakah mereka akan melakukan secara berbeda di waktu yang akan datang? Tentunya masih banyak lagi pertanyaan yang dapat diajukan untuk memberikan umpan balik dan menginvestigasi kelemahan dan kekuatan PBL4C untuk pengajaran.

\section{KESIMPULAN}

Dari pernyataan tersebut dapat ditafsirkan bahwa PBL4C memuat 4 inti area pembelajaran yaitu :

1. Melibatkan berbagai macam ilmu pengetahuan.

Pembelajaran matematika dengan PBL4C tidak hanya terbatas membahas materi yang berkaitan dengan ilmu matematika saja, akan tetapi dalam satu kegiatan pembelajaran guru dapat merancang sebuah pembelajaran yang melibatkan berbagai macam cabang ilmu pengetahuan selain matematika. Jadi, siswa belajar berpikir secara kompleks dimana siswa dapat belajar menyelesaikan suatu permasalahan dengan memperhatikan berbagai pengetahuan awal yang telah diperolehnya dari berbagai sudut pandang ilmu pengetahuan.

2. Melibatkan berbagai macam keterampilan.

Dalam pembelajaran matematika dengan model PBL4C, siswa dapat melatih berbagai macam ketrampilan motoriknya misalnya keterampilan berhitung, berkomunikasi, membuat presentasi, mempresentasikan, membuat perencanaan, mencari informasi, negosiasi, pemecahan masalah dan lain-lain.

3. Melibatkan ketepatan berpikir.

Untuk menyelesaikan sebuah permasalahan diperlukan pemikiran yang tepat. Keterampilan berpikir siswa dapat dilatih dengan berbagai cara diantaranya dengan berlatih membuat perencanaan dalam kehidupan, berpikir analitis, berpikir kritis, berpikir kreatif, melakukan investigasi, membuat keputusan, maupun mengevaluasi.

4. Melibatkan keharmonisan nilai-nilai kehidupan secara umum.

Pembelajaran matematika dengan PBL4C dapat digunakan untuk melatih kecakapan hidup siswa dalam menerapkan nilai-nilai kehidupan secara umum. Nilai nilai kehidupan tersebut antara lain memikirkan keuntungan, semangat kerjasama, perhatian, perdamaian, managemen emosi maupun ego, kerjasama kelompok, tanggung jawab maupun karakterkarakter positif lainnya.

PBL dapat diterapkan dalam kurikulum dan pembelajaran, mengingat pentingnya siswa/siswa memiliki pengalaman dan kemampuan mengatasi masalah nyata dalam kehidupannya seharihari secara mandiri. Adapun kelebihan menggunakan PBL4C, antara lain; (1) Dengan PBL4C akan terjadi pembelajaran bermakna. Belajar dapat semakin bermakna dan dapat diperluas ketika siswa/siswa berhadapan dengan situasi di mana konsep diterapkan; (2) Dalam situasi PBL4C, siswa/siswa mengintegrasikan pengetahuan dan ketrampilan secara simultan dan mengaplikasikannya dalam konteks yang relevan. Artinya, apa yang mereka lakukan sesuai dengan keadaan nyata bukan lagi teoritis sehingga masalah-masalah dalam aplikasi suatu konsep atau teori mereka akan temukan sekaligus selama pembelajaran berlangsung; dan (3) PBL4C dapat meningkatkan kemampuan berpikir kritis, menumbuhkan inisiatif siswa/siswa dalam bekerja, motivasi internal untuk belajar, dan dapat mengembangkan hubungan interpersonal dalam bekerja kelompok.

\section{DAFTAR PUSTAKA}

Arend, R I. (2004). Learning to Teach. New York : Mc Graw Hill Companies.

Cathcart, W. G dkk. (2003). Learning Mathematics in Elementary and 


\section{Hartadi Gatot}

Middle School. Merrill Prentice Hall. United State of America.

Jerry Dwyer (jerry.dwyer@ttu.edu), Robert Byerly dkk. (2005). Assessing the Learning of Proofs in High School. Texas Tech UniversityLubbock, TX, USA.

Karren Schultz-Ferrell dkk. (2006). Introduction to Reasoning and Proof grades 3-5 (The Math Process Standarts Series). United States of America.

Kilpatrick, J., Swafford, J., dan Findell B (eds). (2001). Adding It Up: Helping Children Learn Mathematics. National Academy Press. Washington, DC.

Marmon, W. (2013). PBLAC. Penang : Malaysia.

Moleong, L J. (2007). Metodologi Penelitian Kualitatif. Remaja Rosdakarya : Bandung.
Montague, M \& Applegate, B. (1993). Middle School Students Mathematical Problem Solving: An Analysis of Think-Aloud Protocols. Journalof Council for Learning Disabilities. 16, 29.

Oka Yadnya, I Gusti Agung. (2006). Problematik Pembelajaran Geometri di Sekolah (Laporan Penelitian Tindakan Kelas). Singaraja.

Suyanto. (2009). Urgensi Pendidikan Karakter. Direktorat Jendral Pendidikan Dasar Kementrian Pendidikan Nasional. . (Diakses tanggal 24 Oktober 2011).

Van de Walle, John A. (2008) : Elementary and Middle School Mathematics (Suyono. Penerjemah). Erlangga. Jakarta 